\title{
LIBERDADE E PROXIMIDADE EM LEVINAS
}

Paulo César Nodari*

Ao colega e amigo Evaldo Antônio Kuiava

por ocasião de seu $40^{\circ}$ aniversário natalício.

SÍNTESE - O objetivo deste artigo é mostrar que a concepção de liberdade situa-se no rol da crítica levinasiana à ontologia ocidental e no cenário da ética como filosofia primeira. Levinas concebe, então, a liberdade como acolhimento do Outro. A liberdade deve cessar de manter-se na certeza solitária da supremacia do Mesmo sobre o Outro. Assim, Levinas distancia-se da ontologia e recorre à proximidade não como estado de consciência que conceitua, mas como relação proximal que clama por justiça e responsabilidade.

PALAVRAS-CHAVE - Levinas. Liberdade. Proximidade. Ética. Ontologia. Justiça. Outro.
ABSTRACT - The aim of this article is show that the conception of freedom lies in the roll of levinasian's critique on the occidental ontology and on the scenery of ethics as first philosophy. Levinas conceives freedom as reception of Other. The freedom must cease maintaining on the solitary certainty of the Same's supremacy above Other. Consequently Levinas distances himself from the ontology and runs over the proximity not as state of conscience that judges but as proximate relation that claims for justice and responsability.

KEY WORDS - Levinas. Freedom. Proximity. Ethics. Ontology. Justice. Other

O propósito desta reflexão é tratar liberdade e proximidade no pensamento de Levinas, especialmente, nas obras, Totalité et Infini (TI ${ }^{1}$ e Autrement qu'être ou au-dela de l'essence (AE). ${ }^{2}$ Embora o presente trabalho não se constitua num estudo exaustivo, e, talvez, não apresente grandes novidades aos estudos levinasianos, nós cremos contribuir com a reflexão acerca da compreensão de liberdade no tempo hodierno, uma vez que se constitui num dos temas, há muito tão debatido, mas, ao mesmo tempo, ainda tão suscetível e necessitado de discussão e debate. Trata-se de dizer, em outras palavras, que, não obstante afirmemos ter, por um lado, em nossos dias, consciência aguçada a respeito de liberdade, por outro lado,

* Universidade de Caxias do Sul - paulocesarnodari@hotmail.com.

LÉVINAS, Emmanuel. Totalité et Infini. Essai sur l'estériorité. Paris: Kluwer Academic, s/d, p. 88. De ora em diante, usaremos a abreviação: TI.

Cf. LÉVINAS, Emmanuel. Autrement qu'être ou au-dela de l'essence. Paris: Kluwer Academic, s/d, p. 141. De ora em diante, usaremos a abreviação: AE.

\begin{tabular}{|l|l|l|l|l|l|}
\hline VERITAS & Porto Alegre & v. 51 & n. 2 & Junho 2006 & p. 89-96 \\
\hline
\end{tabular}


podemos dizer, talvez, que nunca tivemos tanta dificuldade em saber exatamente que é liberdade. Quem já não se deparou com perguntas cruciais, como: que é liberdade? Sou livre? Somos livres?

A partir de um viés de leitura muito ortodoxo de Levinas, gostaríamos de apresentar neste estudo uma pequena contribuição para o debate atual em torno da liberdade. A questão da liberdade em Levinas coloca-se no rol de sua crítica à ontologia ocidental, e, portanto, no cenário da ética como filosofia primeira. Levinas concebe a liberdade como acolhimento do Outro. Assim sendo, o início da cons ciência moral dá-se em sua relação necessária e conseqüente com a proximidade. A liberdade deve cessar de manter-se na certeza solitária da supremacia do Mesmo sobre o Outro. Deve superar o imperialismo do Mesmo sobre o Outro, porque a relação com o Outro não se dá mais em termos de domínio e posse. Impõe-se como exigência que domina originalmente a própria compreensão de liberdade, uma vez que a proximidade é o sentido mais profundo da vida humana. É anterior à consciência como caminho de retorno a si, não se tratando, nesse sentido, de negar a consciência, mas de recorrer ao nível prévio do saber, a subjetividade singularizada, a qual já significa proximidade, sensibilidade, vulnerabilidade. Conseqüentemente, dá-se um distanciamento da ontologia, recorrendo-se à proximidade, por conseguinte, não como estado de consciência que conceitua, mas como relação proximal. Nada é mais elevado do que o próximo, e, nesse sentido, a presença do Outro não se choca com a liberdade, mas, pelo contrário, investe-a na perspectiva de convidar o Mesmo à justiça (Cf. TI, p. 88). Em outras palavras, segundo Levinas: "O saber, cuja essência é crítica, não pode reduzir-se ao conhecimento objetivo. Conduz ao Outro. Acolher Outro é colocar minha liberdade em questão" (TI, p. 84). Em outras palavras, é o apelo à responsabilidade e à justiça. Implica na impossibilidade de ser indiferente e apático diante da presença do Outro.

Em Totalité et Infini, especialmente no capítulo, verdade e justiça, Levinas põe em questão a liberdade, perguntando-se "qual é a relação entre a justiça e a verdade?" (TI, p. 80). Assim, para tratar de uma teoria sobre a verdade, urge sair dos parâmetros da tradição ocidental ou mais especificamente do pensamento europeu, da dominação do Mesmo sobre o Outro. Verdade é mais que pura inteligibilidade. Não é mera justificação e nem simples demonstração teorética. Tem a ver com a ordem moral. Trata-se, por conseguinte, de fazer intervir a noção de justiça. É a capacidade de desconfiar de si próprio. É a descoberta da própria fraqueza. É a emergência da consciência da culpabilidade e do fracasso ante o apelo do Outro (Cf. TI, p. 81).

Em contrapartida, a crítica da espontaneidade gerada pela consciência da indignidade moral precede a verdade, precede a consideração do todo e não supõe a sublimação do eu no universal. A consciência da indignidade não é, por sua vez, uma verdade, não é uma consideração do fato. A consciência primeira da minha imoralidade não é a minha subordinação ao fato, mas a Outrem, ao Infinito. A idéia de totalidade e a idéia do Infinito diferem precisamente por isso: a primeira é puramente teorética, a outra é moral. A liberdade, que pode ter vergonha de si própria, fundamenta a verdade (e assim a verdade não se deduz da verdade). Outrem não é inicialmente feito, não é obstáculo, não ameaça de morte. É desejado na minha vergonha. Para descobrir a facticida- 
de injustificada do poder e da liberdade, é preciso não a considerar como objeto, nem considerar Outrem como objeto, é necessário medir-se com o Infinito, isto é, desejá-lo. É preciso ter a idéia do Infinito, a idéia do perfeito, como diria Descartes, para conhecer a sua própria imperfeição. A idéia do perfeito não é idéia, mas desejo. É o acolhimento de Outrem, o começo da consciência moral, que põe em questão a minha liberdade (TI, p. 82).

A existência não está condenada à liberdade. Está, antes, investida como liberdade. É remontar aquém da liberdade (Cf. TI, p. 83). É a capacidade de pôr-se em questão e de superar a evidência do cogito. Em outras palavras, para Levinas, saber está além do conhecimento do cogito. O saber vem de Outrem. O despertar não vem do cogito, mas de Outrem (Cf. TI, p. 85), que não pode ser tematizado, mas tão-somente acolhido.

O acolhimento de Outrem é ipso facto a consciência da minha injustiça - a vergonha que a liberdade sente por si própria. Se a filosofia consiste em saber de uma maneira crítica, ou seja, em procurar um fundamento para a sua liberdade, para justificar, ela começa com a consciência moral em que o Outro se apresenta como Outrem e em que o movimento da tematização se inverte (TI, p. 85).

Para Levinas, o imperialismo do Mesmo, que é toda essência da liberdade (Cf. TI, p. 86), deve ser posto em cheque, porque, na verdade, não posso ter poder sobre Outrem, uma vez que ultrapassa sempre toda idéia que posso ter dele. Outrem é fim de todos os poderes que posso ter sobre ele (Cf. TI, p. 86). "Outrem se impõe como uma exigência que domina essa liberdade e, portanto, como mais original do que tudo o que se passa em mim" (TI, p. 86). Assim, Outrem não deve ser aquele a sobrepujar, a englobar, a dominar. Outrem não deve causar-nos medo. Deve, antes, e, ao contrário, pôr-nos em questionamento. Deve fazer-nos capazes de deixar o âmbito do solitário, isto é, da supremacia do Mesmo sobre o Outro. É importante, então, acolher a Outrem, que se apresenta como presença, como próximo ao Mesmo, convidando-nos, por conseguinte, a sair da indiferença e convocando-nos à justiça.

A presença de Outrem - heteronomia privilegiada - não choca com a liberdade, mas assola-a. A vergonha para si, a presença, e o desejo do Outro, não são a negação do saber: saber é a sua própria articulação. A essência da razão não consiste em assegurar ao homem um fundamento e poderes, mas em pô-lo em questão e em convidá-lo à justiça (TI, p. 88).

Proximidade é o sentido mais profundo da vida humana ${ }^{3}$. É anterior à consciência como caminho de retorno a si. Não se trata de negar a consciência, mas de recorrer o nível prévio do saber, a subjetividade singularizada, a qual já significa proximidade, sensibilidade, vulnerabilidade. "A consciência moral é acolhimento de outrem. A atitude ética, o colocar-se a serviço, sacrifica o eu ao invés de satis-

A reflexão acerca especificamente da temática da proximidade é fundamentalmente parte do texto publicado na Síntese. Cf. NODARI, Paulo César. O rosto como apelo à responsabilidade e à justiça em Levinas. In: Síntese, v. 29, n. 94 (2002): pp. 191-220 
fazê-lo em favor do bem, já justiça e da responsabilidade pelo outro". " Levinas distancia-se da ontologia. Recorre à proximidade que não é estado de natureza e nem estado de consciência. Simplesmente não é estado. Não sendo, portanto, consciência que conceitua. Não é comércio entre um e outro. ${ }^{5}$ Proximidade elevase e vai além do ser. O sentido não vem mais do ser. Não está mais em relação ao ser. É relação proximal. Proximidade significa aproximação. É primordialmente contato e não equacionamento intelectual do contatado. Não é um saber. Constitui-se numa base original possível do saber. Trata-se de uma questão de outra ordem. Subjetividade é, portanto, algo irredutível à consciência e à tematização. Anarquicamente, a proximidade é assim uma relação com uma singularidade sem a mediação de nenhum princípio, de nenhuma idealidade. ${ }^{6}$

Levinas pergunta-se: será acaso a proximidade uma certa medida de intervalos traçados entre dois pontos cuja contigüidade e inclusive a coincidência assinalariam o limite? Se assim fosse, o termo proximidade teria um sentido relativo. Mas, pelo contrário, seu sentido absoluto e próprio supõe a humanidade. Por isso, pode-se até perguntar se a contigüidade mesma seria compreensível sem a proximidade e se a homogeneidade deste espaço seria pensável sem a significação humana da justiça contra toda diferença e, por conseguinte, sem todas as motivações da proximidade, cujo fim é a justiça (Cf. AE, p. 141). ${ }^{7}$ Segundo Levinas, o espaço e a natureza não podem ser colocados em uma impassibilidade geométrica e física iniciais para receber a presença do homem em seus desejos e paixões. Se no começo existissem esta geometria e esta física, os atributos significantes jamais tenderiam a outra coisa senão a uma existência subjetiva na cabeça dos homens e não escaparíamos do narcisismo (Cf. AE, p. 141). Se assim fosse, como entraria, pergunta-se Levinas, a questão da justiça uma vez que esta deriva de uma significação primeira, ou seja, exatamente de uma significação anárquica da proximidade (Cf. AE, p. 141).

A proximidade não é um estado, um repouso, senão, precisamente, inquietude, não-lugar, fora do lugar do repouso que perturba a calma da não-localização do ser que se torna repouso em algum lugar. É sempre insuficiente e jamais demasiadamente próxima. Não se basta numa estrutura fixa, senão que, quando se representa na exigência da justiça como reversível, recai em relação. Converte-se em sujeito. Chega ao seu ponto superlativo, quando desencadeia a inquietude que

E. A. KUIAVA. A significação do rosto (visage) como imperativo ético em Lévinas. In: H. P. de. MORAES FELTES; U. ZILLES. Filosofia. Diálogo de horizontes. Festschrift em homenagem a Jayme Paviani. Caxias do Sul: EDUCS; Porto Alegre: EDIPUCRS, 2001, p. 137.

5 Cf. COSTA, M. L. Levinas. Uma introdução. Petrópolis: Vozes, 2000, p. 170

Cf. SOUZA, R. T. de. Fenomenologia e metafenomenologia: substituição e sentido - sobre o tema da "substituição" no pensamento ético de Levinas, In: SOUZA, R. T. de; OLIVEIRA, N. F. de (Orgs). Fenomenologia Hoje. Porto Alegre: EDIPUCRS, 2001, p. 387

7 "A Justiça consiste em reconhecer em outrem o meu mestre. A igualdade entre pessoas nada significa por si mesma” Para Levinas, somente é possível a existência da justiça se houver privilégio da assimetria sobre a reciprocidade. Justiça não é comparação, não é proporção, mas contínua correção e superação do mero limite fixado por uma lei objetiva. Cf. REY, J-F, Levinas: le passeur de justiça. Paris: Michalon, 1997, p. 56. 
não cessa, convertendo-se em única e, desde este momento, esquecendo completamente da reciprocidade. Trata-se de um amor do qual não se espera correspondência. É o sujeito que se aproxima e que, por conseguinte, constitui uma relação na qual eu participo como termo, porém no qual eu sou mais ou menos que um termo. Este excesso ou este defeito me remete para fora da objetividade da relação. Agora, é preciso falar em primeira pessoa. Eu sou um termo irredutível à relação e, sem dúvida, em uma recorrência que me esvazia de toda consistência.

Levinas, em Autrement qu'être ou au-dela de l'essence, fundamenta a responsabilidade na subjetividade. A subjetividade é rodeada, obsessionada pela alteridade. Existir, então, é suportar, carregar o peso do outro. Responsabilidade, enquanto resposta, é o peso que a subjetividade carrega. Com outras palavras, a responsabilidade qualifica a subjetividade. É o sofrer pelo outro. Significa ser responsável por ele, suportá-lo, estar em seu lugar, consumir-se por ele (Cf. HH, p. 119). ${ }^{8}$ Mais. A subjetividade é responsabilidade pelos outros, vulnerabilidade extrema. O retorno a si faz-se desvio interminável. Bem antes da consciência da escolha, o homem aproxima-se do homem. É tecido de responsabilidade. ${ }^{9}$

A proximidade não se resolve na consciência que um ser adquire de outro ser ao qual estimaria próximo enquanto encontrar-se-ia à sua vista ou ao seu alcance e enquanto seria possível captá-lo, tê-lo ou entretê-lo na reciprocidade do aperto de mãos, da carícia, da colaboração, do comércio ou da conservação. Proximidade não está no saber e tampouco na reciprocidade. Proximidade é não-indiferença à presença do outro que me olha. A diferença constitui-se, portanto, como não indiferença e a ruptura com o sistema da reciprocidade como obsessão (Cf. AE, p. 143). A obsessão, enquanto não-reciprocidade e afecção de sentido único irreversível como a diacronia do tempo que escapa entre os dedos, anula-se em mim nomeando-me em primeira pessoa, isto é, eu sou responsável pelo outro desde sempre. Na perspectiva levinasiana, o humano não nasce nem na decisão nem na obediência. O humano é uma possibilidade que nasce do questionamento do ser, da saída da dimensão ontológica. O humano introduz um sentido à ontologia. A ética surge, exatamente, quando ninguém pode responder em meu lugar.

Ser autêntico significa, então, vencer o medo de superar o esquecimento da responsabilidade ao chamado e de encontrar a dimensão verdadeira do existir e do pensar. ${ }^{10}$ É o movimento em direção ao outro em sentido único, sem preocupação

Cf. LEVINAS, Emmanuel. Humanismo do outro homem. Petrópolis: Vozes, 1993. De ora em diante, usaremos a abreviação: HH.

9 Cf. FABRI, Marcelo. Desencantando a ontologia: subjetividade e sentido ético em Levinas. Porto Alegre: EDIPUCRS, 1997, p. 120. "A subjetividade é um vazio mais vazio que nada, é um órgão em déficit, como pulmão vazio, mas cujo movimento é in-spiração: o outro é animação e inspiração, que provoca uma exaltação e uma encarnação. A subjetividade é um vazio como de útero materno, mais vazio do que o vácuo, porque em déficit. É lugar para outro, plataforma, suporte que porta, suporta e já sofre desde o outro e para o outro que só vem ao presente para ser seio do tempo outro" (SUSIN, Luis Carlos. Levinas e a reconstrução da subjetividade. In: Véritas, v. 37, n. 147, 1992, p. 376).

Cf. M. FABRI, Levinas e a busca do autêntico. In: SOUZA, R. T. de; OLIVEIRA, N. F. de (Orgs). Fenomenologia Hoje, p. 77. 
do movimento de volta. É aproximar-se de tal maneira que, acima de todas as relações recíprocas que não deixam de se estabelecer entre eu e o próximo, eu sempre tenho dado um passo a mais até ele. Isto somente é possível se este passo é responsabilidade, de tal modo que na responsabilidade existente em mim com relação ao outro, eu sempre tenho uma resposta a mais para responder à sua própria responsabilidade. Logo, responsabilidade não é coincidência e muito menos retorno. É sempre abertura. É o dar-se inexoravelmente. ${ }^{11}$

Ser eu (Moi) significa, a partir daí, não se poder furtar à responsabilidade, como se todo o edifício da criação repousasse sobre meus ombros. Mas a responsabilidade esvazia o Eu (Moi) de seu imperialismo e de seu egoísmo - seja ele egoísmo da salvação não o transforma em momento da ordem universal, porém confirma a unicidade do Eu (Moi). A unicidade do Eu (Moi) é o fato de que ninguém pode responder em meu lugar (HH, p. 61).

Todavia, não basta, segundo Levinas, insistir na ruptura da coincidência. Urge romper com a estrutura da sincronia por meio da diferença do Mesmo e do Outro na não-indiferença da obsessão exercida pelo Outro sobre o Mesmo (Cf. AE, p. 146). Em Levinas, o privilégio da proximidade com relação à ordem racional, a qual tende, em princípio, a um sistema de puras relações, é a hipóstase da relação em subjetividade obsessionada por uma obsessão não-recíproca até o próximo. Assim, a subjetividade não é algo prévio à proximidade na qual se comprometeria ulteriormente. Ao contrário, a proximidade, como relação e termo, é o lugar no qual se tece todo compromisso. É, provavelmente, a partir da proximidade que se deve tratar o problema da subjetividade, visto ser esta uma responsabilidade pelos outros, uma vulnerabilidade extrema (Cf. HH, p. 124). "A subjetividade do sujeito é a vulnerabilidade, a exposição à afecção, sensibilidade, passividade mais passiva que qualquer passividade" (AE, p. 103). Em Levinas, a subjetividade do sujeito é a sensibilidade como vulnerabilidade. É, enquanto passividade acusativa, resposta a um chamado, a qual, perpassada pelo outro, é marcada pelo infinito. Ou seja, o outro está imediatamente no cerne da subjetividade precedendo a própria identidade já que tudo se produz previamente ao despertar da consciência. ${ }^{12}$

A proximidade não é reflexão sobre o estado de alma do eu que se aproxima do próximo. Não é, portanto, uma configuração que se produz na alma. É imediatez mais antiga que a abstração da natureza. É tampouco uma fusão. É um contato do outro e neste estar em contato não se trata de investir contra o outro, a fim de anular sua alteridade nem de suprimir o eu no outro, pois o próximo não se deixa preceder por nenhum precursor e apresenta-se dentro de uma contingência que exclui todo a priori (Cf. AE, p. 148). Assim sendo, o próximo me concerne

11 "A responsabilidade é, paradoxalmente, de fora para dentro; ela inverte a tendência de procurar a possibilidade da comunicação em um ir de dentro para fora desde a coincidência da consciência consigo mesma” (SOUZA, R. T. de. Fenomenologia e metafenomenologia: substituição e sentido sobre o tema da "substituição" no pensamento ético de Levinas, p. 400).

2 Cf. P. S. PIVATTO, Responsabilidade e culpa em Emmanuel Levinas. In: R. T. de SOUZA e N. F. de OLIVEIRA (Orgs.), Fenomenologia Hoje, p. 313. 
antes de toda assunção, antes de todo compromisso sentido ou rechaçado. É o primeiro a vir sem anúncio de nivelamento, antes de qualquer relação contratada, à margem de qualquer parentesco ou lógica. O próximo não me concerne por ser reconhecido como pertencente ao mesmo gênero que eu, mas, antes, pelo contrário, porque é precisamente outro. O próximo é irmão. É fraternidade irrecusável. É impossibilidade de recusa (Cf. AE, p. 148). Marca-me antes que eu o designe. É o gemido do humano totalmente outro.

Na aproximação, eu sou, desde sempre, servidor do próximo, chego sempre já demasiado tarde e culpado deste atraso. Estou como que ordenado desde fora, traumaticamente, por uma autoridade que me dirige. Não é a consciência nem uma espécie de consciência que me faz devedor da chegada em atraso ao próximo. Porque a proximidade está à margem da representação, da ontologia, do logos. O próximo não se mantém em uma forma. É o totalmente outrem. Nada é mais elevado do que o próximo e, enquanto tal, não pode deixar-me indiferente. "O próximo me golpeia antes mesmo de golpear-me, como se já o tivesse ouvido antes mesmo de falar-me" (AE, p. 150).

De acordo com Levinas, a proximidade mais próxima expressa-se no rosto do outro que me olha. O rosto é responsabilidade irrecusável que antecede todo consentimento livre, todo pacto e todo contrato (Cf. AE, p. 150). "Responsabilidade que não escolhemos, mas à qual somos convocados e eleitos (...)" ${ }^{13}$ Escapa a toda representação. O descobrimento do rosto é nudez, não-forma, abandono de si, envelhecimento, morrer. O rosto é o mais nu que a nudez. É vestígio de si mesmo. Minha reação frustra uma presença que já é passado de si mesma. É lapso de envelhecimento já perdido, que escapa a toda retenção e altera minha contemporaneidade com o outro. Este outro reclama antes mesmo que eu venha. É atraso sempre irrecuperável. Minha presença não responde à extrema urgência do vencimento. Sou acusado de ter demorado. Mediante esta miséria, o rosto do próximo me obsessiona. "Quanto mais respondo mais responsável sou; quanto mais me aproximo, cuja carga carrego, mais distante estou" (AE, p. 157). Nada mais me é indiferente. O olhar torna-se imperativo. E isso, segundo Pivatto, "inaugura o humanismo do outro homem". ${ }^{14}$

Assim sendo, para concluir, situados no cenário da ética como filosofia primeira, não é possível compreender liberdade e proximidade, segundo Levinas, senão profundamente interligadas. Liberdade, antes de ser consciência moral do Mesmo e possibilidade de escolha livre sem coação externa de quem quer que seja, é acolhimento do Outro que vem a mim. É abertura total a Outrem. É vulnerabilidade. É pura passividade. ${ }^{15}$ É convocação à responsabilidade para com o Outro, totalmente

13 C. DI SANTE. Instituição da responsabilidade radical. São Paulo: Paulus, 2005, p. 28.

P. S. PIVATTO, Ética da alteridade. In: M. A. de OLIVEIRA. Correntes fundamentais da ética contemporânea. Petrópolis: Vozes, 2000, p. 90

15 "O sujeito da passividade é o sujeito nomeado que é tomado pela exterioridade, no cerne de seu mundo interior, tendo que responder a uma voz de antes do próprio nome, endividado em relação a quem chama, de um chamado que tem prioridade em relação à mobilidade do repouso e do caráter tético do si e da atividade do verbo" (M. L. PELIZZOLI. Levinas. A reconstrução da subjetividade. Porto Alegre: EDIPUCRS, 2002, p. 178). 
vulnerável. É apelo à justiça. É convite à saída da estabilidade do meu mundo. Significa comprometer-se, ou, em outras palavras, não ficar indiferente à realidade de Outrem que me interpela constantemente para fazer-lhe justiça sem, contudo, esperar ante ao compromisso que tenho de responder-lhe ao apelo de justiça, reciprocidade. É, enfim, compromisso. É, segundo Levinas, total e puro des-interessamento, do qual a única preocupação é com a vida do Outro, que se aproxima e clama por justiça, já que, para Levinas, o Mesmo tem uma obrigação ética perante o Outro. E esse ir ao Outro se constitui, por conseguinte, como responsabilidade absoluta. ${ }^{16}$

\section{Referências}

COSTA, M. L. Levinas. Uma introdução. Petrópolis: Vozes, 2000, p. 170.

DI SANTE, C. Instituição da responsabilidade radical. São Paulo: Paulus, 2005.

FABRI, Marcelo. Desencantando a ontologia: subjetividade e sentido ético em Levinas. Porto Alegre: EDIPUCRS, 1997

LÉVINAS, Emmanuel. Autrement qu'être ou au-dela de l'essence. Paris: Kluwer Academic, s/d.

Humanismo do outro homem, Petrópolis: Vozes, 1993, p. 124.

Totalité et Infini. Essai sur l'estériorité. Paris: Kluwer Academic, s/d.

MORAES FELTES, H. P. de; U. ZILLES. Filosofia. Diálogo de horizontes. Festschrift em homenagem a Jayme Paviani. Caxias do Sul: EDUCS; Porto Alegre: EDIPUCRS, 2001.

NODARI, Paulo César. O rosto como apelo à responsabilidade e à justiça em Levinas. In: Síntese, v. 29, n. 94 (2002): pp. 191-220.

OLIVEIRA, Manfredo Araújo de. Correntes fundamentais da ética contemporânea. Petrópolis: Vozes, 2000 .

PIVATTO, P. S. A nova proposta ética de Emmanuel Levinas. In: Cadernos da FAFIMC, n. 13 (1995): pp. 47-62.

A Ética de Levinas e o sentido do humano: crítica à Ética Ocidental e seus pressupostos. In: Veritas, v. 37, n. 147 (1992): pp. 353-367.

Ser moral ou não ser humano. In: Veritas, v. 44, n. 2 (1999): pp. 353-367.

PELIZZOLI, M. L. Levinas. A reconstrução da subjetividade. Porto Alegre: EDIPUCRS, 2002.

PENZO, G.; GIBELLINI, R. (Org.). Deus na filosofia do século XX. São Paulo: Loyola, 1998.

REY, J-F. Levinas: le passeur de justiça. Paris: Michalon, 1997, p. 56.

SOUZA, R. T. de. Sentido e alteridade. Dez ensaios sobre o pensamento de Emmanuel Levinas. Porto Alegre: EDIPUCRS, 2000.

; OLIVEIRA, N. F. de (Orgs). Fenomenologia Hoje. Porto Alegre: EDIPUCRS, 2001.

SUSIN, Luis Carlos. Levinas e a reconstrução da subjetividade. In: Véritas, v. 37, n. 147, 1992.

16 Cf. BACCARINI, E. Emmanuel Lévinas (1905-). Dizer Deus “outramente”. In: G. PENZO; R. GIBELLINI (Org.). Deus na filosofia do século XX. São Paulo: Loyola, 1998, p. 432. 